asked about the job title and exposures in the respondent's longest held job only, which adds to potential misclassification as some participants may have experienced significant exposures in other jobs but may be classified as unexposed. Both types of exposure misclassification would lead to underestimating the true effects of occupational exposures to dusts, vapours and fumes on COPD. The benefit of asking about exposure in the longest held job is that those who have already left the industry with exposures-perhaps because of respiratory symptoms-are correctly classified as having had relevant exposure, thus diminishing the healthy worker bias. Another potential limitation of the study is misclassification of the outcome, as some subjects with asthma who smoke may be labelled as having COPD, although recent studies have shown that smoking also increases the risk of asthma. ${ }^{22}$ If a considerable proportion of COPD cases actually had asthma related to occupational exposures, this could lead to overestimation of risk. However, as the JEM classification was modified to be COPD-specific, this is not likely to be a major bias in the study.

The findings by Blanc and colleagues underline the fact that both occupational exposures and smoking should be addressed in the primary prevention of COPD at the population level. This means measures to reduce levels of dusts, vapours, gases and fumes in workplaces and enhancement of tobacco control measures directed at populations of working age. Workers with such occupational exposures should get information and education about adverse effects related to their workplace exposures and on the intensifying effect of smoking. The same strategies could be applied in secondary prevention when advising and treating individual patients with chronic bronchitis or more advanced COPD. Longitudinal and intervention studies using these strategies in clinical settings should be conducted in the future to provide information on what methods are most effective in practice and how these approaches influence the prognosis of COPD

A question remaining open is whether this study, ${ }^{21}$ along with other recent studies on occupational exposures and smoking, ${ }^{16}{ }^{18}$ should influence our practice of diagnosing occupational COPD. This needs open-minded discussion that should perhaps also touch on such sensitive issues as compensation for disability from occupational COPD in smokers. It seems clear that being a smoker can no more mean that the individual does not have occupational COPD, as smokers appear to be at an even higher risk of developing work-related COPD than non-smokers.

Competing interests: None.

Thorax 2009;64:1-2. doi:10.1136/thx.2008.104778

\section{REFERENCES}

1. British Thoracic Society. The burden of lung disease. 2nd ed. London: British Thoracic Society, 2006.

2. Pauwels RA, Buist AS, Calverley PMA, et al. Global strategy for diagnosis, management and prevention of chronic obstructive pulmonary disease. NHLBI/WHO Global Initiative for Chronic Obstructive Lung Disease (GOLD) workshop summary. Am J Respir Crit Care Med 2001:163:1256-76.

3. Murray C, Lopez A. Evidence-based health policy: lessons from the Global Burden of Disease Study. Science 1996;274:740-3.

4. Fletcher $\mathbf{C}$, Peto R. The natural history of chronic airflow obstruction. BMJ 1977;1:1645-8.

5. US Public Health Service. The health consequences of smoking. Chronic obstructive lung disease. A report of the Surgeon General. Rockville, MD: US Department of Health and Human Services, Public Health Service, Office of Smoking and Health, 1984:1-512

6. Fletcher $\mathbf{C}$. Disability and mortality from chronic bronchitis in relation to dust exposure. AMA Arch Ind Health 1958; 18:368-73.

7. Trupin L, Earnest G, San Pedro M, et al. The occupational burden of chronic obstructive pulmonary disease. Eur Respir J 2003;22:462-9.
8. Becklake MR. Occupational exposures: evidence for a causal association with chronic obstructive pulmonary disease. Am Rev Respir Dis 1989;140:S85-91.

9. Burge PS. Occupation and chronic obstructive pulmonary disease (COPD). Eur Respir J 1994; 7:1032-4.

10. Krzyzanowski M, Jedrychowski W, Wysocki M. Factors associated with change in ventilatory function and development of chronic obstructive pulmonary disease in a 13-year follow-up of the Cracow study: risk of chronic obstructive pulmonary disease. Am Rev Respir Dis 1986;134:1011-9.

11. Lebowitz M. Occupational exposures in relation to symptomatology and lung function in a community population. Environ Res 1977;44:59-67.

12. Korn RJ, Dockery DW, Speizer FE, et al. Occupational exposures and chronic respiratory symptoms: a population-based study. Am Rev Respir Dis 1987;136:298-301.

13. Viegi G, Prediletto R, Paoletti P, et al. Respiratory effects of occupational exposure in a general population sample in North Italy. Am Rev Respir Dis 1991;143:510-5.

14. Fishwick D, Bradshaw LM, D'Souza W, et al. Chronic bronchitis, shortness of breah, and airway obstruction by occupation in New Zealand. Am J Respir Crit Care Med 1997:156:1440-6.

15. Post WK, Heederik D, Kromhout $\mathrm{H}$, et al. Occupational exposures estimated by a population specific job exposure matrix and 25 year incidence rate of chronic non-specific lung disease (CNSLD): the Zutphen Study. Eur Respir J 1994;7:1032-4.

16. Zock J-P, Sunyer J, Kogevinas M, et al. Occupation chronic bronchitis, and lung function in young adults. An international study. Am J Respir Crit Care Med 2001;163:1572-7.

17. Hnizdo E, Sullivan PA, Moon Bang K, et al Association between chronic obstructive pulmonary disease and employment by industry and occupation in the US population: a study of data from the third National Health and Nutrition Examination Survey. Am J Epidemiol 2002:156:738-46.

18. De Meer G, Kerkhof M, Kromhout $\mathrm{H}$, et al. Interaction of atopy and smoking on respiratory effects of occupational dust exposure: a general population-based study. Environ Health 2004;3:6

19. Harber P, Tashkin DP, Simmons M, et al. Effect of occupational exposures on decline of lung function in early chronic obstructive pulmonary disease. Am J Respir Crit Care Med 2007:176:994-1000.

20. Balmes J, Becklake M, Blanc P, et al. ATS statement: Occupational contribution to the burden of airway disease. Am J Respir Crit Care Med 2003; 167:787-97.

21. Blanc PD, Iribarren C, Trupin L, et al. Occupational exposures and the risk of COPD: dusty trades revisited. Thorax 2009;64:6-12.

22. Piipari R, Jaakkola JJK, Jaakkola N, et al. Smoking and asthma in adults. Eur Respir J 2004;24:734-9.

\title{
Beyond airflow limitation: another look at COPD
}

\section{Massimo Pistolesi}

Correspondence to: Professor M Pistolesi, Section of Respiratory Medicine, Department of Critical Care, University of Florence, Viale GB Morgagni 85, 50134 Firenze, Italy; massimo.pistolesi@unifi.it
More than 40 years ago Benjamin Burrows and his colleagues ${ }^{1}$ described the distinctive clinical, functional, radiological and pathological characteristics of the chronic obstructive pulmonary disease (COPD) phenotypes that they called emphysematous and bronchial types of chronic airways obstruction. They identified a subgroup of patients who were "thin" and had evidence of emphysema on chest $x$ ray, while another subgroup was found to be of "stocky build" and had chest $x$ ray changes suggestive of previous pulmonary inflammatory disease. Postmortem anatomical emphysema severity was positively 
related to emphysema grade on chest $x$ ray, and with total lung capacity and age. Anatomical emphysema was, on the other hand, inversely related to chronic inflammatory changes on chest $x$ ray, and with sputum volume, carbon dioxide tension and diffusing capacity. ${ }^{1}$ All patients had severe irreversible airways obstruction and died of respiratory failure but, noticeably, reduction in forced expiratory volume in $1 \mathrm{~s}\left(\mathrm{FEV}_{1}\right)$ was not significantly related to anatomical emphysema extent and severity. Burrows et al introduced the terms type $\mathrm{A}$ and type $\mathrm{B}$ to empirically differentiate patients with the emphysematous type from those with the bronchial type of chronic airways obstruction. ${ }^{1}$ This phenotypic differentiation of patients with COPD, without being not even seriously questioned or challenged, has never been widely accepted and in more recent times it has been almost totally neglected by the pulmonary scientific community.

In this issue of Thorax, investigators from the Universities of Kyoto, Shiga, and Vancouver, ${ }^{2}$ continuing a long history of research activity in the field of the in vivo anatomical study of COPD by high resolution computed tomography (HRCT), elegantly bring back to life and strengthen Burrows' findings of 1966 (see page 20). ${ }^{2}$ Ogawa and colleagues ${ }^{2}$ found, indeed, that patients with COPD who, at HRCT, had reduced $x$ ray attenuation values, compatible with emphysematous destruction of lung parenchyma, were thinner than those who had bronchial wall thickening compatible with chronic inflammatory changes of the conductive airways. A significant inverse relationship was found between body mass index (BMI) and emphysema extent at HRCT, whereas no correlation was present between BMI and thickness of the bronchial wall. FEV 1 was inversely correlated with BMI, HRCT emphysema extent and bronchial wall thickness, but there was no significant difference in mean $\mathrm{FEV}_{1}$ between the two HRCT phenotypes of COPD. ${ }^{2}$

These findings point to the fact that patients with COPD may have different systemic clinical manifestations, reflecting different pathophysiological mechanisms of expiratory airflow limitation. Several other papers ${ }^{3-6}$ have shown a reduction in BMI in patients with HRCT findings of predominant emphysema but the study of Ogawa and colleagues $^{2}$ is the only one in which HRCT quantitative parameters related to both destruction of lung parenchyma ${ }^{7}$ and airways remodelling ${ }^{8}$ have been measured in a large series of patients with COPD.

Spirometric detection of not fully reversible airflow limitation by $\mathrm{FEV}_{1}$ is the integral result of a spectrum of different underlying pathological conditions that are unified under the acronym COPD. The use of this term has permitted the pulmonary community to speak a common language and to increase the awareness in the general public and the health system authorities of one of the present and future world leading causes of chronic morbidity and mortality. Nonetheless, diagnosing, categorising and measuring disease progression by spirometric parameters such as $\mathrm{FEV}_{1}$ and forced vital capacity (FVC), as suggested by recent guidelines, cannot provide a panoramic view of the complexity of COPD. ${ }^{9-11}$ Like many other common diseases, COPD is a heterogeneous disorder. ${ }^{12-16}$ However, no other specialists would diagnose and classify specific diseases by rudimentary standards as pulmonologists do with COPD. ${ }^{17}$ As highlighted by Burge ${ }^{18}$ commenting on the results of clinical trials with inhaled corticosteroids over the past decade, it is likely that the different pathological changes underlying COPD may respond differently to inhaled steroids. The results of these studies could have been different if patients had been subdivided into subgroups according to their clinical presentation, instead of being enrolled by the level of airflow limitation alone. ${ }^{18}$ The same explanation may hold true for the deceiving results of more recent pharmacological trials. ${ }^{19} 20$

There is growing evidence that HRCT could provide in vivo information about the various pathological changes occurring in patients with COPD and may permit differentiation of those with predominant airway obstruction from those with predominant emphysematous destruction. The same group of investigators who report in this issue of Thorax have previously shown that pulmonary function abnormalities are more accurately predicted by multivariate regression with HRCT measurements of both extent of low attenuation areas and airway wall thickening than by univariate regression with low attenuation areas. ${ }^{21}$ Furthermore, they have also shown that thickening of large airways, assessed from the percentage wall area of the right apical segmental bronchus, as in the present paper, is related to thickening of the airways with an internal diameter smaller than $2 \mathrm{~mm}$, as assessed by histological evaluation. ${ }^{8}$ In this line of evidence it can be said that wall thickness of the large airways at HRCT can predict the anatomical status of small airways, the major site of airway obstruction in COPD. ${ }^{22}$ Together with the extent of low attenuation areas, wall thickness of the large airways on HRCT can then be used to help classify patients with airflow limitation as having either a predominant phenotype of increased airway resistance or a predominant phenotype of increased lung compliance. Orlandi and colleagues ${ }^{23}$ measured both airway wall thickness and lung parenchyma $x$ ray attenuation by HRCT and showed that patients with chronic productive cough had significantly thicker bronchial walls than patients without chronic productive cough who, on the other hand, had a significant increase in the percentage lung area with reduced $x$ ray attenuation and a lower lung diffusing capacity. Accordingly, O'Donnell and colleagues ${ }^{24}$ found that sputum neutrophil counts in patients with COPD was closely related to airway dysfunction, but not to the severity of emphysema, as assessed by HRCT and lung diffusing capacity.

The paper by Ogawa and colleagues ${ }^{2}$ offers a demonstration of how the overall picture of COPD could be complex and shows to what extent the unifying spirometric assessment of expiratory airflow limitation could be of limited value in order to identify different pathophysiological mechanisms among individuals. Using HRCT as a criterion standard to identify the two more relevant phenotypes of COPD and extending the observation, apart from BMI, towards several other clinical, functional and instrumental variables (ie, symptoms, physical signs, functional evaluation at rest and during exercise, quality of life, frequency of exacerbations, chest $x$ ray findings, biological markers in expired air, sputum and blood) and, eventually, to genetic differences, could facilitate recognition of patients with COPD whose responsiveness to a specific therapeutic approach may be different. The development of a standardised method for classifying COPD phenotypes in clinical practice may have a great impact in understanding the results of pharmacological trials, on the clinical approach to patient treatment and our knowledge of the natural history of the disease. Such a methodology is strongly required. ${ }^{25}$ Attempts to define the COPD clinical phenotypes have been published in the past year by several groups of investigators. ${ }^{4-6}{ }^{26}$ More relevant data are expected from ongoing prospective large scale clinical trials, such as the 
ECLIPSE $^{11}$ and the NIH funded COPDGene Project.

It is not essential to solve the dilemma of whether the term COPD expresses correctly the protean clinical presentations of the same disease or that it combines different clinical entities, but it is necessary to realise that there are needs and research opportunities in an area that is largely unknown. The words "expiratory airflow limitation" expresses our present inaccuracy in differentiating increased airway resistance from increased lung compliance. ${ }^{27}$ HRCT studies have shown that at least two radiological patterns exist in which either airway obstruction or emphysematous destruction predominate. Ogawa and colleagues ${ }^{2}$ have convincingly demonstrated that, regardless of expiratory airflow limitation, the different pathological changes seen in vivo by HRCT are brought by people with different body habits. Let us jump over the hindering barrier of airflow limitation and explore the COPD world beyond!

Competing interests: None.

Thorax 2009;64:2-4. doi:10.1136/thx.2008.106674

\section{REFERENCES}

1. Burrows B, Fletcher CM, Heard BE, et al. The emphysematous and bronchial types of chronic airways obstruction. A clinicopathological study of patients in London and Chicago. Lancet 1966;87:830-5.
2. Ogawa E, Nakano $Y$, Ohara $T$, et al. Body mass index in male patients with COPD: correlation with low attenuation area on CT. Thorax 2009;64:20-25.

3. Kitaguchi Y, Fujimoto K, Kubo K, et al. Characteristics of COPD phenotypes classified according to the findings of HRCT. Respir Med 2006;100:1742-52.

4. Makita H, Nasuhara Y, Nagai K, et al. Characterisation of phenotypes based on severity of emphysema in chronic obstructive pulmonary disease. Thorax 2007;62:932-7.

5. Lee YK, Oh YM, Lee JH, et al. Quantitative assessment of emphysema, air trapping, and airway thickening on computed tomography. Lung 2008:186:157-65

6. Pistolesi M, Camiciottoli G, Paoletti $\mathbf{M}$ et al. Identification of a predominant phenotype of COPD in clinical practice. Respir Med 2008;102:367-76.

7. Madani A, Zanen J, de Maertelaer V, et al. Pulmonary emphysema: objective quantification at multidetector row CT. Comparison with macroscopic and microscopic morphometry. Radiology 2006;238:1036-43.

8. Nakano Y, Wong JC, de Jong PA, et al. The prediction of small airway dimensions using computed tomography. Am J Respir Crit Care Med 2005;171:142-6.

9. Gelb AF, Hogg JC, Müller NL, et al. Contribution of emphysema and small airways in COPD. Chest 1996;109:353-9.

10. Nishimura K, Izumi T, Tsukino M, et al. Dyspnea is a better predictor of 5-year survival than airway obstruction in patients with COPD. Chest 2002; 121:1434-40.

11. Vestbo J, Anderson W, Coxson HO, et al. Evaluation of COPD longitudinally to identify predictive surrogate end-points (ECLIPSE). Eur Respir J 2008;31:869-73.

12. Wedzicha JA. The heterogeneity of chronic obstructive pulmonary disease. Thorax 2000:55:631-2.

13. Friedlander $\mathbf{A L}$, Linch $\mathrm{D}$, Dyar $\mathrm{LA}$, et al. Phenotypes of chronic obstructive pulmonary disease. COPD: J Chronic Obstructive Pulm Dis 2007:4:355-84.
14. Vestbo J. COPD, diagrams and traditions: time to move on? Thorax 2008;63:755-6.

15. Rennard SI, Vestbo J. The many "Small COPDs": COPD should be an orphan disease. Chest 2008;134:623-7.

16. Reilly JJ. COPD and declining $\mathrm{FEV}_{1}$ - time to divide and conquer. N Engl J Med 2008;359:1616-18.

17. de Marco R. What evidence could validate the definition of COPD? Thorax 2008;63:756-7.

18. Burge PS. Euroscop, Isolde, and the Copenhagen City Lung Study. Thorax 1999:54:287-8.

19. Calverley PM, Anderson JA, Celli B, et al. Salmeterol and fluticasone propionate and survival in chronic obstructive pulmonary disease. N Engl J Med 2007;22:356:775-89

20. Tashkin DP, Celli B, Senn S, et al. A 4-year trial of tiotropium in chronic obstructive pulmonary disease. N Engl J Med 2008;359:1548-54.

21. Nakano Y, Muro S, Sakai H, et al. Computed tomographic measurements of airway dimensions and emphysema in smokers. Correlation with lung function. Am J Respir Crit Care Med 2000; 162:1102-8.

22. Hogg JC, Macklem PT, Thurlbeck WM. Site and nature of airways obstruction in chronic obstructive lung disease. N Engl J Med 1968;278:1355-60.

23. Orlandi I, Moroni C, Camiciottoli G, et al. Chronic obstructive pulmonary disease: thin-section CT measurement of airway wall thickness and lung attenuation. Radiology 2005;234:604-10.

24. O'Donnell RA, Peebles C, Ward JA, et al. Relationship between peripheral airway dysfunction, airway obstruction, and neutrophilic inflammation in COPD. Thorax 2004:59:837-42.

25. Croxton TL, Weinman GG, Senior RM, et al. Clinical research in chronic obstructive pulmonary disease. Needs and opportunities. Am J Respir Crit Care Med 2003;167:1142-9.

26. Marsh SE, Travers J, Weatherall M, et al. Proportional classification of COPD phenotypes. Thorax 2008;63:761-7.

27. Hogg JC, Pierce RA. Remodelling of peripheral lung tissue in COPD. Eur Respir J 2008;31:913-14.

\section{Statins for the treatment of asthma: a discovery well, dry hole or just snake oil}

\section{Bruce K Rubin}

Until the 1906 Food and Drug Act in the USA, it was common for travelling salesman to move from town to town selling miraculous cures in the form of patent medicines. With the wide spread promotion of Clark Stanley's Snake Oil Liniment, the term "snake oil" became a widely accepted derogatory phrase for ineffective patent medications sold with

Correspondence to: Dr Bruce K Rubin, Wake Forest University School of Medicine, Medical Center Blvd, Winston-Salem, North Carolina 27157-1081, USA; brubin@wfubmc.edu claims for curing an extraordinarily variety of illnesses. ${ }^{1}$

Statins are inhibitors of the 3-hydroxy3-methylglutaryl coenzymes A (HMGCoA) reductase. These are among the most widely prescribed medications in the world today. Statins are dramatically effective, treating hyperlipidaemia and preventing cardiovascular disease, particularly in high risk populations. ${ }^{2}$ Statins have also been shown in the laboratory to have impressive immunomodulatory effects. $^{3}$ These drugs suppress $\mathrm{T}$ helper (Th) 1 cell development and promote Th2 polarisation from CD4 cells in vitro. ${ }^{4}$ Statins act as direct inhibitors of major histocompatibility antigen (MHC) class 2 expression and interferon $\gamma(\mathrm{IFN} \gamma)$ and thus inhibit $\mathrm{T}$ cell activation. ${ }^{5}$

In animal models, statins can ameliorate Th1 inflammatory disorders such as collagen induced arthritis and are being considered as a promising therapy for rheumatoid arthritis. ${ }^{6}$ They have also been shown to be effective in models of autoimmune encephalomyelitis, ${ }^{7}$ inflammatory colitis ${ }^{8}$ and even psoriasis. ${ }^{9}$

There have also been experimental and clinical observations related to the use of statins for the treatment of lung disease. McKay et al showed that high dose simvastatin $(40 \mathrm{mg} / \mathrm{kg})$ attenuated eosinophil driven inflammation in a murine model of ovalbumin induced asthma. This was mediated, at least in part, by suppressing $\mathrm{T}$ lymphocyte secretion of interleukin (IL) 4 and IL5. ${ }^{10}$ Samson et al showed that fluvastatin decreased peripheral blood mononuclear cell proliferation 